\title{
PROCEEDINGS OF ELMAR-2017
}

$59^{\text {th }}$ International Symposium ELMAR-2017 18-20 September 2017, Zadar, Croatia

\section{EDITED BY}

\section{Mario Muštra Dijana Vitas Branka Zovko-Cihlar}

University of Zagreb

Faculty of Electrical Engineering and Computing Department of Wireless Communications Unska 3 / XII 10000 Zagreb CROATIA 
Published by: $\quad$ Faculty of Electrical Engineering and Computing, University of Zagreb

Edited by: $\quad$ Mario Muštra, Dijana Vitas, Branka Zovko-Cihlar

Front Cover: $\quad$ Painting by artist Mrs Ljerka Njerš

Printed by: $\quad$ LotusGRAF, Zagreb

ISBN: $\quad 978-953-184-230-3$

ISSN: $\quad 1334-2630$

IEEE Catalog Nr.: CFP17825-PRT

(C) by Croatian Society Electronics in Marine - ELMAR, Zadar, 2017.

All rights reserved. No part of this publication may be reproduced, stored in a retrieval system or transmitted in any form or by any means, electronic, mechanical, photocopying, recording or otherwise, without the prior written permission from the Croatian Society Electronics in Marine - ELMAR, Zadar.

The papers appearing in this book comprise the proceedings of the meeting mentioned on the cover and title page. They reflect the authors' opinions and are published as presented and without change, in the interests of timely dissemination. Their inclusion in this publication does not necessarily constitute endorsement by the editors or by the Croatian Society Electronics in Marine - ELMAR, Zadar.

Printed in Croatia. 


\section{(*) Elmar}

$59^{\text {th }}$ International Symposium ELMAR-2017 is organised by:

Croatian Society Electronics in Marine - ELMAR, Zadar

University of Zagreb Faculty of Electrical Engineering and Computing,

Department of Wireless Communications

\section{ELMAR-2017 symposium General Sponsor}

Ministry of Maritime Affairs, Transport and Infrastructure of the Republic of Croatia

\section{ELMAR-2017 symposium Sponsors}

Ministry of Science and Education of the Republic of Croatia

Tankerska plovidba d.d.

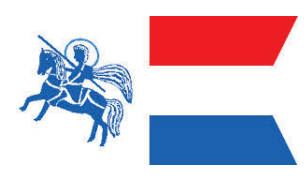

Town of Zadar

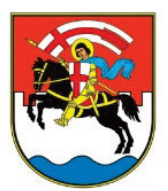

OiV - Transmitters and Communications Ltd.

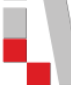

HRT - Croatian Radiotelevision 
ELMAR-2017 symposium takes place under the co-sponsorship of:

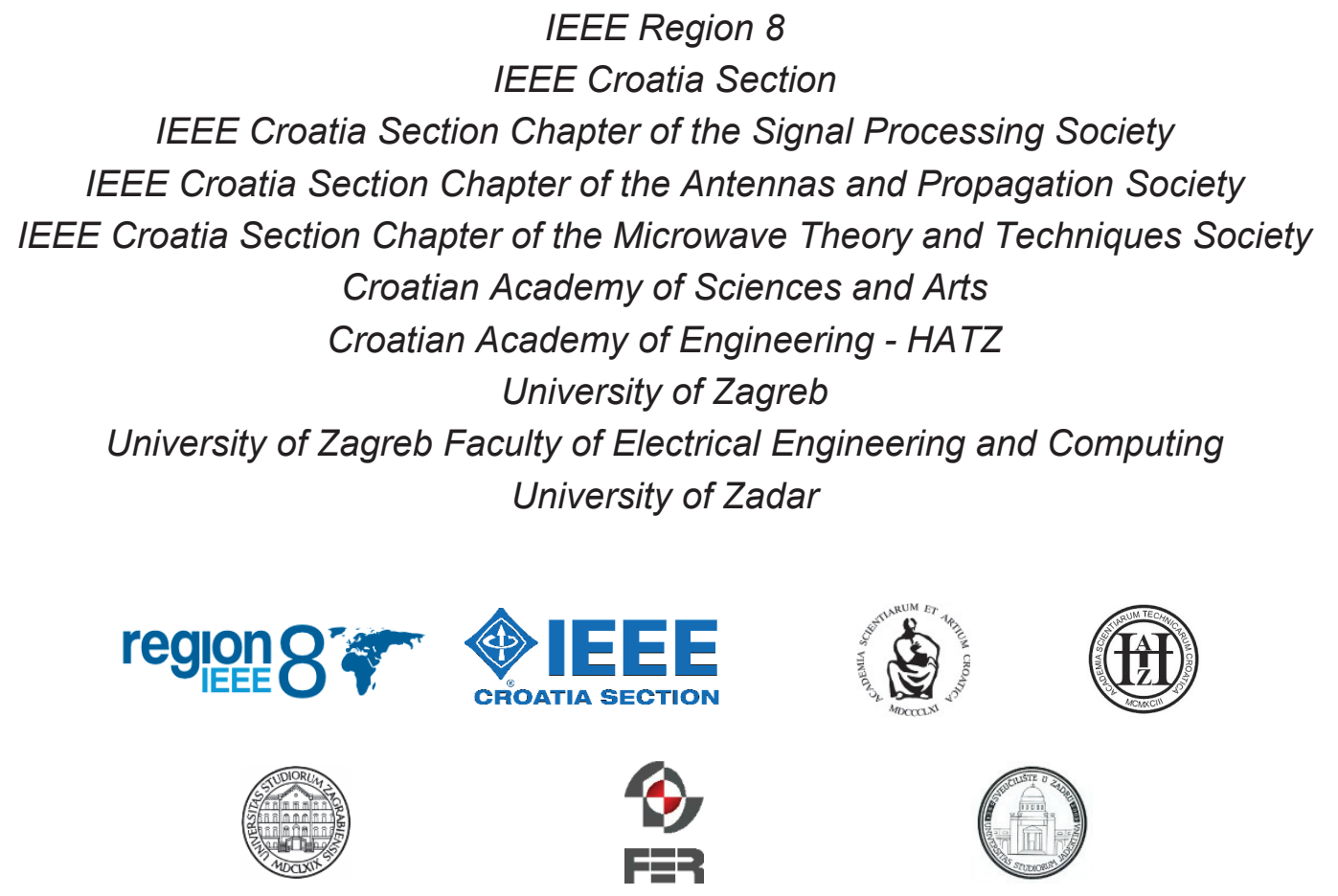

ELMAR-2017 symposium is supported by:

ZADAR TOURIST BOARD

COUNTY OF ZADAR

FALKENSTEINER BORIK ZADAR CROATIA

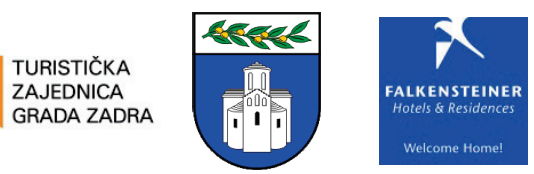




\title{
ELMAR-2017 SYMPOSIUM COMMITTEES
}

\author{
General Chair \\ Branka Zovko-Cihlar, University of Zagreb, Croatia \\ Program Chair \\ Mislav Grgić, University of Zagreb, Croatia

\section{ELMAR-2017 SYMPOSIUM INTERNATIONAL PROGRAM COMMITTEE} \\ Mario Muštra, Croatia \\ Zdeněk Němec, Slovak Republic \\ Miloš Oravec, Slovak Republic \\ Jarmila Pavlovičova, Slovak Republic \\ Fernando Pereira, Portugal \\ Jan Pidanič, Slovak Republic \\ Pavol Podhradský, Slovak Republic \\ Kamisetty R. Rao, USA \\ Darko Ratkaj, Switzerland \\ Fabiana Rodrigues Leta, Brasil \\ Gregor Rozinaj, Slovak Republic \\ Markus Rupp, Austria \\ Gerald Schaefer, United Kingdom \\ Mubarak Shah, USA \\ Shiguang Shan, China \\ Thomas Sikora, Germany \\ Karolj Skala, Croatia \\ Ryszard Stasinski, Poland \\ Luis Torres, Spain \\ Frantisek Vejrazka, Czech Republic \\ Dijana Vitas, Croatia \\ Stamatis Voliotis, Greece \\ Krzysztof Wajda, Poland \\ Nick Ward, United Kingdom \\ Branka Zovko-Cihlar, Croatia
}

Juraj Bartolić, Croatia

Narcis Behlilović, Bosnia and Herzegovina

David Broughton, United Kingdom

Aura Conci, Brasil

Marek Domanski, Poland

Janusz Filipiak, Poland

Borko Furht, USA

Mohammed Ghanbari, United Kingdom

Mislav Grgić, Croatia

Sonja Grgić, Croatia

Ho Yo-Sung, Korea

Bernhard Hofmann-Wellenhof, Austria

Ebroul Izquierdo, United Kingdom

Aggelos K. Katsaggelos, USA

Ana Katalinić Mucalo, Croatia

Ismail Khalil, Austria

Tomislav Kos, Croatia

Murat Kunt, Switzerland

Igor Kuzle, Croatia

Panos Liatsis, United Kingdom

Rastislav Lukac, Canada

Lidija Mandić, Croatia

Branka Medved Rogina, Croatia

Borivoj Modlic, Croatia

Marta Mrak, United Kingdom 


\section{ELMAR-2017 SYMPOSIUM INTERNATIONAL REVIEW COMMITTEE}

Winton Afrić, Croatia

Codruta Ancuti, Italy

Goran Bakalar, Croatia

Sanja Bauk, Montenegro

Alen Begović, Bosnia and Herzegovina

Narcis Behlilović, Bosnia and Herzegovina

Marko Bosiljevac, Croatia

Jelena Božek, Croatia

Miloš Brajović, Montenegro

Jasmina Čaušević, Croatia

Emil Dumić, Croatia

Juraj Fosin, Croatia

Irena Galić, Croatia

Branimir Ivšić, Croatia

Juraj Kačur, Slovakia

Ana Katalinić-Mucalo, Croatia

Jan Kufa, Czech Republic

Hrvoje Leventić, Croatia

Časlav Livada, Croatia

Sadko Mandžuka, Croatia

Marta Mrak, United Kingdom
Mario Muštra, Croatia

Zdeněk Němec, Slovakia

Miloš Oravec, Slovakia

Jarmila Pavlovičová, Slovakia

Juraj Petrović, Croatia

Jan Pidanič, Slovakia

Pavol Podhradský, Slovakia

Michal Reznicek, Czech Republic

Renata Rybárová, Slovakia

Gregor Rozinaj, Slovakia

Markus Rupp, Austria

Tomás Shejbal, Czech Republic

Mladen Sokele, Croatia

Isidora Stanković, Montenegro

Zvonimir Šipuš, Croatia

Namir Škaljo, Bosnia and Herzegovina

Dijana Vitas, Croatia

Mario Vranješ, Croatia

Josip Vuković, Croatia

Radovan Zentner, Croatia

Branka Zovko-Cihlar, Croatia

\section{ELMAR-2017 SYMPOSIUM ORGANISING COMMITTEE}

Mislav Grgić, Croatia Mario Muštra, Croatia Jelena Božek, Croatia
Dijana Vitas, Croatia

Josip Vuković, Croatia 


\section{ELMAR-2017 PROGRAM}

\begin{tabular}{|c|c|c|}
\hline $\begin{array}{c}\text { Monday, } \\
\text { September } 18\end{array}$ & $\begin{array}{c}\text { Tuesday, } \\
\text { September } 19\end{array}$ & $\begin{array}{l}\text { Wednesday, } \\
\text { September } 20\end{array}$ \\
\hline $\begin{array}{l}\text { 8:30 - 16:30 } \\
\text { Registration }\end{array}$ & $\begin{array}{l}\text { 9:00 - 11:30 } \\
\text { Registration }\end{array}$ & $\begin{array}{l}\text { 9:00 - 11:30 } \\
\text { Registration }\end{array}$ \\
\hline $\begin{array}{l}\quad \text { 9:00 - 9:30 } \\
\text { OPENING SESSION: } \\
\text { Welcome Speeches }\end{array}$ & $\begin{array}{c}9: 00-11: 15 \\
\text { Special Session } 3 \text { and } \\
\text { Session } 3\end{array}$ & $\begin{array}{c}9: 00-10: 30 \\
\text { Sessions } 6 \& 7\end{array}$ \\
\hline $\begin{array}{c}\text { 9:30 - 10:00 } \\
\text { Welcome Cocktail }\end{array}$ & $\begin{array}{c}\text { 11:15 - 11:30 } \\
\text { Session Break }\end{array}$ & $\begin{array}{c}\text { 10:30 - 11:00 } \\
\text { Session break }\end{array}$ \\
\hline $\begin{array}{l}\text { 10:15 - 12:30 } \\
\text { PLENARY SESSION: } \\
\text { Keynote Talks }\end{array}$ & $\begin{array}{l}\text { 11:30 - 12:30 } \\
\text { Session } \mathbf{4} \& \mathbf{5}\end{array}$ & $\begin{array}{c}\text { 11:00 - 12:30 } \\
\text { Sessions } 8 \text { \& } 9\end{array}$ \\
\hline $\begin{array}{l}\text { 12:30 - 14:00 } \\
\text { Lunch Break }\end{array}$ & \multirow{3}{*}{$\begin{array}{l}\text { 13:00 - 20:00 } \\
\text { Excursion by Ship* } \\
\text { *Lunch on board }\end{array}$} & $\begin{array}{l}\text { 12:30 - 14:00 } \\
\text { Lunch Break }\end{array}$ \\
\hline $\begin{array}{c}14: 15-17: 00 \\
\text { Special Sessions } 1 \& 2 \\
\text { and Sessions } 1 \& 2\end{array}$ & & $\begin{array}{c}14: 00-16: 30 \\
\text { Sessions } 10 \& 11\end{array}$ \\
\hline $\begin{array}{c}17: 15-20: 00 \\
\text { Guided Zadar Sightseeing }\end{array}$ & & 15:45 Closing Session \\
\hline $\begin{array}{c}21: 00 \\
\text { ELMAR-2017 Symposium } \\
\text { Gala Dinner }\end{array}$ & $\begin{array}{l}20: 30 \\
\text { Dinner }\end{array}$ & \\
\hline
\end{tabular}




\section{ELMAR-2017 PROGRAM}

\section{Monday, 18 September 2017}

\begin{tabular}{|c|c|}
\hline $8: 30-16: 30$ & Registration \\
\hline \multicolumn{2}{|c|}{ HALL A } \\
\hline \multicolumn{2}{|c|}{ OPENING SESSION: Welcome Speeches } \\
\hline \multirow{2}{*}{\multicolumn{2}{|c|}{$\begin{array}{c}\text { 09:30 - 10:00 WELCOME COCKTAIL } \\
\text { Bar at Hotel "Donat" }\end{array}$}} \\
\hline & \\
\hline \multicolumn{2}{|c|}{ HALL A } \\
\hline \multicolumn{2}{|c|}{ 10:15 - 12:30 PLENARY SESSION: Keynote Talks } \\
\hline \multicolumn{2}{|c|}{$12: 30-14: 00 \quad$ Lunch Break } \\
\hline HALL A & HALL B \\
\hline $\begin{array}{c}14: 15-15: 45 \\
\text { SPECIAL SESSION 1: } \\
\text { Intelligent Transport Systems }\end{array}$ & $\begin{array}{c}14: 15-15: 45 \\
\text { SESSION 1: } \\
\text { Multimedia Communications }\end{array}$ \\
\hline $\begin{array}{c}\text { 16:00 - 17:00 } \\
\text { SPECIAL SESSION 2: } \\
\text { Computer Vision for New Emerging } \\
\text { Applications }\end{array}$ & $\begin{array}{c}\text { 16:00 - 17:00 } \\
\text { SESSION 2: } \\
\text { Wireless Communications } 1\end{array}$ \\
\hline \multicolumn{2}{|c|}{$\begin{array}{c}17: 15-20: 00 \\
\text { GUIDED ZADAR SIGHTSEEING } \\
\text { Meeting Point: Hotel "Funimation", Main Entrance, 17:15 }\end{array}$} \\
\hline \multicolumn{2}{|c|}{$\begin{array}{l}\text { ELMAR-2017 SYMPOSIUM GALA DINNER } \\
\text { Meeting Point: Hotel "Funimation", 21:00 }\end{array}$} \\
\hline
\end{tabular}




\section{ELMAR-2017 PROGRAM}

\section{Tuesday, 19 September 2017}

\begin{tabular}{|c|c|}
\hline $9: 00-11: 30$ & Registration \\
\hline HALL A & HALL B \\
\hline $\begin{array}{l}\text { 9:00 - 11:15 } \\
\text { SPECIAL SESSION 3: } \\
\text { Radar Systems }\end{array}$ & $\begin{array}{c}\text { 9:00 - 11:15 } \\
\text { SESSION 3: } \\
\text { Speech and Audio Processing }\end{array}$ \\
\hline \multicolumn{2}{|l|}{$11: 15-11: 30$} \\
\hline $\begin{array}{c}\text { 11:30 - 12:30 } \\
\text { SESSION 4: } \\
\text { Wireless Communications } 2\end{array}$ & $\begin{array}{c}\text { 11:30 - 12:30 } \\
\text { SESSION 5: } \\
\text { Image Processing } 1\end{array}$ \\
\hline \multicolumn{2}{|c|}{$\begin{array}{c}\text { EXCURSION BY SHIP } \\
\frac{\text { Meeting Point: Hotel "Funimation", Main Entrance, 12:45 }}{\text { Lunch will be served on board the ship }}\end{array}$} \\
\hline \multicolumn{2}{|c|}{$\begin{array}{c}20: 30 \\
\text { DINNER }\end{array}$} \\
\hline
\end{tabular}




\section{ELMAR-2017 PROGRAM}

Wednesday, 20 September 2017

\begin{tabular}{|c|c|}
\hline \multicolumn{1}{|c|}{$9: 00-11: 30$} & Registration \\
\hline HALL A & HALL B \\
\hline $\begin{array}{c}\text { 9:00 - 10:30 } \\
\text { SESSION 6: } \\
\text { Telecommunications }\end{array}$ & $\begin{array}{c}9: 00-10: 30 \\
\text { SESSION 7: }\end{array}$ \\
\hline \multicolumn{1}{|c|}{$10: 30-11: 00$} & Session Break \\
\hline 11:00 - 12:30 & 11:00 - 12:30 \\
SESSION 8: & SESSION 9: \\
Image Processing 2 & Smart Systems \\
\hline \multicolumn{1}{|c|}{$12: 30-14: 00$} & Lunch Break \\
\hline 14:00 - 15:30 & SESSION 11: \\
SESSION 10: & Sea Ecology \\
\hline Navigation Systems & \\
\hline & 15:45 CLOSING SESSION \\
\hline
\end{tabular}




\section{Monday, 18 September 2017}

8:30 - 16:30 Registration

HALL A

Monday, 18 September 2017

9:00 - 9:30 OPENING SESSION: Welcome Speeches

Session Chairs: Branka Zovko-Cihlar, Mario Muštra

$9: 30-10: 00$

WELCOME COCKTAIL

Bar at Hotel "Donat"

10:15 - 12:30 PLENARY SESSION: Keynote Talks

Session Chair: Branka Zovko-Cihlar

Prof. Panos Liatsis, Department of Electrical Engineering, The Petroleum Institute UAE

Patient-Specific Blood Flow Modelling in the Assessment of Functional Stenosis Severity

Tigran Vržina, Transmitters \& Communications Ltd., CROATIA

Impact of Transition from Analog (FM) to Digital (DAB+) Sound Broadcasting on

Environmental Preservation

Prof. Peter Planinšič, University of Maribor, Faculty of Electrical Engineering and Computer Science, SLOVENIA

SAR-images Analysis and Applications

12:30 - 14:00 $\quad$ Lunch Break 
Session Chairs: Mario Muštra, Sadko Mandžuka

Borna Kapusta, Mladen Miletić, Edouard Ivanjko, Miroslav Vujić; CROATIA

Preemptive Traffic Light Control based on Vehicle Tracking and Queue Lengths

Daniel Pavleski, Daniela Koltovska-Nechoska, Edouard Ivanjko; MACEDONIA/ CROATIA

Evaluation of Adaptive Traffic Control System UTOPIA using Microscopic Simulation

Krešimir Vidović, Sadko Mandžuka, Davor Brčić; CROATIA

Estimation of Urban Mobility using Public Mobile Network

Emir Žunić, Almir Djedović, Dženana Đonko; BOSNIA AND HERZEGOVINA

Cluster-based analysis and time-series prediction model for reducing the number of traffic accidents

Tomislav Erdelić, Tonči Carić, Martina Ravlić; CROATIA

Predicting Waiting Times at Intersections

Pero Škorput, Hrvoje Vojvodić, Sadko Mandžuka; CROATIA

Cyber Security in Cooperative Intelligent Transportation Systems

16:00 - 17:00 SPECIAL SESSION 2: Computer Vision for New Emerging Applications

Session Chairs: Irena Galić, Časlav Livada

Hrvoje Leventić, Danilo Babin, Lazar Velicki, Irena Galić, Vladimir Zlokolica; CROATIA/BELGIUM/SERBIA

Semi-automatic Left Atrial Appendage Segmentation from 3D CCTA Images

Krešimir Romić, Irena Galić, Tomislav Galba; CROATIA

Technology Assisting the Blind - Routing on the Staircases Using Wide-angle Camera

Časlav Livada, Miro Proleta, Krešimir Romić, Hrvoje Leventić; CROATIA

Beyond the Touch: a Web Camera based Virtual Keyboard

Monika Andonová, Jarmila Pavlovičová, Slavomír Kajan, Miloš Oravec, Veronika Kurilová; SLOVAKIA

Diabetic Retinopathy Screening Based on CNN

$17: 15-20: 00$

GUIDED ZADAR SIGHTSEEING

Meeting Point: Hotel "Funimation", Main Entrance, 17:15

21:00 
14:15 - 15:45 SESSION 1: Multimedia Communications

Session Chairs: Sonja Grgić, Jarmila Pavlovičová

Petra Dražić; CROATIA

The Propagation of Ka-Band Signals Through the Atmosphere

Srećko Kunić, Zoran Šego, Branka Zovko Cihlar; CROATIA

Analysis of Audio and Video Synchronization in TV Digital Broadcast Devices

liams Bajčinovci, Mario Vranješ, Danijel Babić, Branimir Kovačević; CROATIA/SERBIA

Subjective and Objective Quality Assessment of MPEG-2, H.264 and H.265 Videos

16:00 - 17:00 SESSION 2: Wireless Communications 1

Session Chair: Marko Bosiljevac

Martin Matis, Dominik Nezník, Dávid Hrabčák, L'ubomír Doboš, Ján Papaj; SLOVAKIA

Intelligent Channel Assigning in CR-MANET based on Spectrum Sensing

Dávid Hrabčák, Martin Matis, Dominik Nezník, L’ubomír Doboš, Ján Papaj; SLOVAKIA

Proposal of Simple Metrics for Evaluation of Social Ties in Mobility Models for MANET Networks

Botond Sandor Kirei, Calin Farcas, Robert Groza, Marina Dana Topa; ROMANIA An All-Digital Frequency Locked Loop and its Linearized s-domain Model

$17: 15-20: 00$

21:00
GUIDED ZADAR SIGHTSEEING

Meeting Point: Hotel "Funimation", Main Entrance, 17:15

ELMAR-2017 SYMPOSIUM GALA DINNER

Meeting Point: Hotel "Funimation", bar at the pool, 21:00 


\section{Tuesday, 19 September 2017}

9:00-12:30 Registration

\section{HALL A}

9:00 - 11:15

\section{SPECIAL SESSION 3: Radar Systems}

Session Chairs: Winton Afrić, Jan Pidanič

Tomáš Hnilička, Tomáš Zálabský, Vitezslav Krčmar; CZECH REPUBLIC

Design of Power Hybrid Structures for a N-port Power Combiner

Mirko Jukl, Siniša Lacković, Fran Pregernik; CROATIA

Digital Simulator of Radar Targets and Clutter for Surveillance Radar System

Michal Rezniček; CZECH REPUBLIC

Doppler CW Radar Signal Processing, Implementation and Analysis

Luboš Rejfek, Ondrej Fišer, David Matousek, Ladislav Beran, Pavel Chmelar; CZECH REPUBLIC

Correction of Received Power for Doppler Measurements by FMICW Radars

Luboš Rejfek, Ondrej Fišer, David Matousek, Ladislav Beran, Pavel Chmelar; CZECH REPUBLIC

Sensitivity Analysis of PCDR35 Radar

Tomáš Zálabský, Pavel Bezousek; CZECH REPUBLIC

Phase Interferometry for Approach Radars

Tomáš Zálabský, Pavel Bezousek, Tomáš Hnilička; CZECH REPUBLIC

An Antenna Array Synthesis for Large Vertical Aperture Antenna for Secondary Surveillance Radar

11:15 - 11:30 Session Break 
Session Chairs: Sonja Zentner Pilinsky

Jan Pidanič, Vojtech Valenta, Karel Juryca; CZECH REPUBLIC

The Radio Coverage Monitoring by Low-Cost System based on SDR

Srushti Shetty, Siniša Lacković, Sonja Zentner Pilinsky; INDIA/CROATIA

4G Coverage Analysis of Main Croatian Roads

Yury V. Yukhanov, Tatiana Y. Privalova; RUSSIA

Electromagnetic Scattering of Plane H-Polarized Wave by an Antenna Array of Loaded Planar Waveguides

Andrej Galoić, Branimir Ivšić, Davor Bonefačić; CROATIA

Rectifier for Energy Harvesting Application

Dominik Barbarić, Marko Bosiljevac, Zvonimir Šipuš; CROATIA

Realization of Distributed Optical-Fiber Temperature Sensor

Sanja Bauk, Jose Angel Leon Calvo, Rudolf Mathar, Anke Schmeink;

MONTENEGRO/GERMANY

V2P/I Communication for Increasing Occupational Safety at a Seaport

13:00 - 20:00 EXCURSION BY SHIP

Meeting Point: Hotel "Funimation", Main Entrance, 12:45

Lunch will be served on ship 
9:00 - 11:15 SESSION 3: Speech and Audio Processing

Session Chairs: Gregor Rozinaj, Juraj Kacur

Rustam Latypov, Ruslan Nigmatullin, Evgeni Stolov; RUSSIA

Instantaneous Frequency and Detection of Dynamics in Speech

Juraj Kacur; SLOVAKIA

Gradual Enhancement of GMM for Speaker Identification

Tomáš Koctúr, Stanislav Ondáš, Jozef Juhár; SLOVAKIA

Speech Corpus Generation Based on N-gram Confidence Measure Classification

Marianna Rosinová, Martin Lojka, Ján Staš, Jozef Juhár; SLOVAKIA

Voice Command Recognition Using EEG Signals

Jan Staš, Daniel Hladek, Jozef Juhar; SLOVAKIA

Semantic Indexing and Document Retrieval for Personalized Language Modeling

Isidora Stanković, Cornel loana, Miloš Daković; MONTENEGRO/FRANCE

High-Resolution Local Polynomial Fourier Transform in Acoustic Signal Analysis

11:15-11:30 Session Break

11:30 - 12:30 SESSION 5: Image Processing 1

Session Chairs: Sonja Grgić, Jelena Božek

Matteo Brisinello, Ratko Grbić, Matija Pul, Tihomir Anđelić; CROATIA/SERBIA Improving Optical Character Recognition Performance for Low Quality Images

Dzenan Lapandić, Jasmin Velagić, Haris Balta; BOSNIA AND HERZEGOVINA/ BELGIUM

Framework for Automated Reconstruction of 3D Model from Multiple 2D Aerial Images

Emina Hadrović, Dinko Osmanković, Jasmin Velagić; BOSNIA AND HERZEGOVINA Aerial Image Mosaicing Approach Based on Feature Matching

Jozef Goga, Slavomír Kajan; SLOVAKIA

Hand Gesture Recognition Using 3D Sensors

13:00 - 20:00 EXCURSION BY SHIP

Meeting Point: Hotel "Funimation", Main Entrance, 12:45

Lunch will be served on ship 


\section{Wednesday, 20 September 2017}

9:00-15:30 Registration

\section{HALL A}

$9: 00-10: 30$

SESSION 6: Telecommunications

Session Chair: Pavol Podhradský

Viktor Stoynov, Zlatka Valkova-Jarvis; BULGARIA

Aggregated Assessment of Downlink Resource Scheduling Techniques in Indoor Environments via a Comparative Factor

Alen Begović, Namir Škaljo, Narcis Behlilović; BOSNIA AND HERZEGOVINA

On Using Various Local Loop Types in Recent VDSL Applications

Yevgeniya Sulema, Gregor Rozinaj; SLOVAKIA

WebRTC-based 3D Videoconferencing System

Juraj Londák, Martin Medvecký, Pavol Podhradský; SLOVAKIA

Virtual SDN and NFV Laboratory - Architecture and Implementation

Andjela Draganić, Irena Orović, Srdjan Stanković; MONTENEGRO

Spread-Spectrum-Modulated Signal Denoising based on Median Ambiguity Function

10:30 - 11:00 Session Break

11:00 - 12:30 SESSION 8: Image Processing 2

Session Chairs: Lidija Mandić, Mario Muštra

Jozef Gerát, Dominik Sopiak, Miloš Oravec, Jarmila Pavlovičová; SLOVAKIA

Vehicle Speed Detection from Camera Stream using Image Processing Methods

Zuzana Bukovčiková, Dominik Sopiak, Miloš Oravec, Jarmila Pavlovičová; SLOVAKIA

Face Verification Using Convolutional Neural Networks with Siamese Architecture

Moustafa M. Kurdi, Alex K. Dadykin, Imad A. Elzein; BELARUS

Proposed Encryption Method of Quadcopter's Video Transmitted to Underwater Robot by Using Block Packet Cipher

Ante Poljicak, Davor Donevski, Lidija Mandic; CROATIA

Applicability of the GCR Masking in an Image Watermarking Method 
12:30 - 14:00 $\quad$ Lunch Break

14:00 - 15:30 SESSION 10: Navigation Systems

Session Chair: Tomislav Kos

Dimitar Dichev, Hristofor Koev, Dimitar Diakov, Nikolay Panchev, Rosica Miteva, Hristiyana Nikolova; BULGARIA

Automated System for Calibrating Instruments Measuring Parameters of Moving Objects

Jelena Petrović, Mladen Viher; CROATIA

Radar GIS for Site Acceptance Testing

Benjamin Weinert, Mathias Uslar, Axel Hahn; GERMANY

System-of-Systems: How the Maritime Domain can learn from the Smart Grid 
9:00 - 10:30 SESSION 7: Power Electronics and Automation

Session Chair: Snježana Rimac-Drlje

Michal Reznicek; CZECH REPUBLIC

Humidity Field Estimation

Andrzej Firlit, Krzysztof Kołek, Krzysztof Piątek; POLAND

Rapid Controller Development for a Dynamic Voltage Restorer

Andrzej Firlit, Krzysztof Kołek, Krzysztof Piątek; POLAND

Heterogeneous Active Power Filter Controller

Nedim Osmić, Jasmin Velagić; BOSNIA AND HERZEGOVINA

Design of a Simple Service Oriented Supervisory Control and Data Acquisition System

10:30 - 11:00 Session Break

11:00 - 12:30 SESSION 9: Smart Systems

Session Chairs: Dijana Vitas, Juraj Petrović

Tomas Krejci, Michal Mandlik; CZECH REPUBLIC

Implementation of the Communication Chain for Education

Juraj Petrović, Dijana Vitas, Predrag Pale; CROATIA

Experiences with Supervised vs. Unsupervised Online Knowledge Assessments in Formal Education

Petar Taler, Safet Hamedović, Mirta Benšić, Emmanuel Karlo Nyarko; CROATIA/BOSNIA AND HERZEGOVINA

LeArEst - The Software for Border and Area Estimation of Data Measured with Additive Error

Juha Niemi, Juha T. Tanttu; FINLAND

Automatic Bird Identification for Offshore Wind Farms: A Case Study for Deep Learning

Dušan Gleich, Peter Planinšič, Danijel Šipoš, Marko Malajner; SLOVENIA

Deep Convolutional Neural Networks for SAR Patch Categorization

Zoja Vulaj, Miloš Brajović, Anela Draganić, Irena Orović; MONTENEGRO

Detection of Irregular QRS Complexes using Hermite Transform and Support Vector Machine 
14:00 - 15:30 SESSION 11: Sea Ecology

Session Chair: Irena Jurdana

Goran Bakalar, Myriam Beatriz Baggini, Sebastian Gabriel Bakalar; USA

Protection of Adriatic Sea: Declaring New Nature Parks and New Protected Areas in Central Adriatic Region

Renato Ivče, Sanjin Valčić, Irena Jurdana; CROATIA

Assessment and Prediction Model of Ballast Water Management

Goran Bakalar, Myriam Beatriz Baggini, Sebastian Gabriel Bakalar; USA

Comparisons of Remote FCM Analysis System and Ordinary Analytical Methods for Identification of BW Content

Lorenzo Manzoli, Aldo Franco Dragoni, Andrea Bonci, Paolo Sernani, Massimiliano Pirani, Nicola Falcionelli; ITALY

A Boat-Based Flying Drone to Monitor Coastlines and Render them in Augmented Reality 


\title{
Semi-automatic Left Atrial Appendage Segmentation from 3D CCTA Images
}

\author{
Hrvoje Leventić ${ }^{1}$, Danilo Babin ${ }^{2}$, Lazar Velicki ${ }^{3}$, Irena Galić ${ }^{1}$ and Vladimir Zlokolica ${ }^{4}$ \\ ${ }^{1}$ Faculty of Electrical Engineering, Computer Science and Information Technology, University of Osijek, Croatia \\ 2 imec-IPI-UGent, Faculty of Engineering and Architecture, Ghent University, Belgium \\ ${ }^{3}$ Institute for Cardiovascular Diseases, Sremska Kamenica, Serbia \\ ${ }^{4}$ Faculty of Technical Sciences, University of Novi Sad, Serbia \\ hrvoje.leventic@etfos.hr
}

\begin{abstract}
Left Atrial Appendage closure is a relatively novel percutaneous procedure for patients suffering from Atrial Fibrillation (AF). LAA closure has only recently been approved for clinical use and preparations for closure procedures are in most hospitals performed by manual segmentation of Coronary CT Angiography (CCTA) images. We present a novel semiautomatic LAA segmentation method using two seed points (starting and stopping points for segmentation) and manually selected threshold. The method performs the visualization of the segmented LAA and enables a doctor to select 3 points which define a plane in 3D space (the ostium) where the LAA will be occluded.

Performance of the proposed method is evaluated on 8 CCTA datasets manually segmented by a cardiovascular surgeon. Proposed method achieves an average DICE coefficient of $91.7 \%$ on evaluation datasets.
\end{abstract}

Keywords-CCTA; LAA; Left atrial appendage segmentation; Centerline detection

\section{INTRODUCTION}

Atrial Fibrillation (AF) is a cardiac disease associated with a high risk of stroke. Some research suggests that it is responsible for almost $20 \%$ of all strokes [1], with the vast majority of cardiac thrombii formed in left atrial appendage [2]. It is estimated that there is over 33 million people worldwide suffering from atrial fibrillation [3] and that number is expected to increase with the increasing age of population, especially in the developed countries. Common method for stroke prevention in patients with AF is anticoagulation therapy which reduces risk of stroke by $\sim 60 \%$ [4], but patients who are at higher risk of stroke are also more likely to have contraindications to anticoagulation therapy [5].

Left atrial appendage closure, a relatively novel method of stroke prevention in patients with $\mathrm{AF}$, has recently been shown as non-inferior to anticoagulation therapy [6]. All closure devices are available in several predefined sizes and an appropriately sized device for each patient has to be selected for the procedure. This means that to be able to choose appropriately sized device, doctors require accurate measurements of LAA. Several most important measurements are: diameter and shape of the ostium, LAA morphology, number of lobes, angle of the dominant lobe, etc. It has been shown that LAA measurements derived from CCTA images are superior to TEE derived measurements [7] when it comes to choosing the appropriate size of the device.
To the best of our knowledge, all state of the art methods measure the required LAA dimensions manually, either from $2 \mathrm{D}$ slices or from $3 \mathrm{D}$ volume by manual (interactive) segmentation. A semi-automatic method for LAA segmentation proposed in [8] requires manual selection of four fiducial points to obtain LAA bounding box, from which a pool of segmentation proposals is generated for each 2D slice. Afterwards, best 2D proposal for each slice is selected using random forest regression and all selected 2D proposals are merged into a 3D model using spatial continuity. The work proposed in [9] focuses on automatic whole heart isolation, where the focus is not on the segmentation of the LAA, but on the removal of the LAA from the segmented whole heart image for visualization of coronary arteries and bypass arteries.

Our proposed method requires a user to select two seed points and determine threshold value for segmentation. The method is robust to threshold value selection and "leaks" which can occur after thresholding when other anatomical structures (e.g. pulmonary vein) are in close proximity to LAA and their intensity values are similar.

This paper is organized in following sections: section 2 deals with the implementation details of the proposed method, section 3 shows the evaluation of the proposed method on our datasets, while section 4 is used for the discussion and gives the concluding remarks about the proposed method.

\section{Proposed Method}

Our proposed method performs a semi-automatic segmentation of left atrial appendage. Method requires a user to select two seed points: first inside the LAA and second inside left atrium, outside the LAA. After that user selects a threshold value and starts the segmentation. Method performs a multi step spherical region growing algorithm to segment the LAA. After the segmentation a segmented model is visualized. The user selects 3 points on the model which determine the location of LAA ostium, and algorithm cuts the model at plane determined by the 3 points.

The segmentation method consists of four steps: centerline detection, initial spherical segmentation based on detected centerline, additional iterative decreasing radii segmentation and addition of isolated components. Every step of this method is performed in $3 \mathrm{D}$ space. 


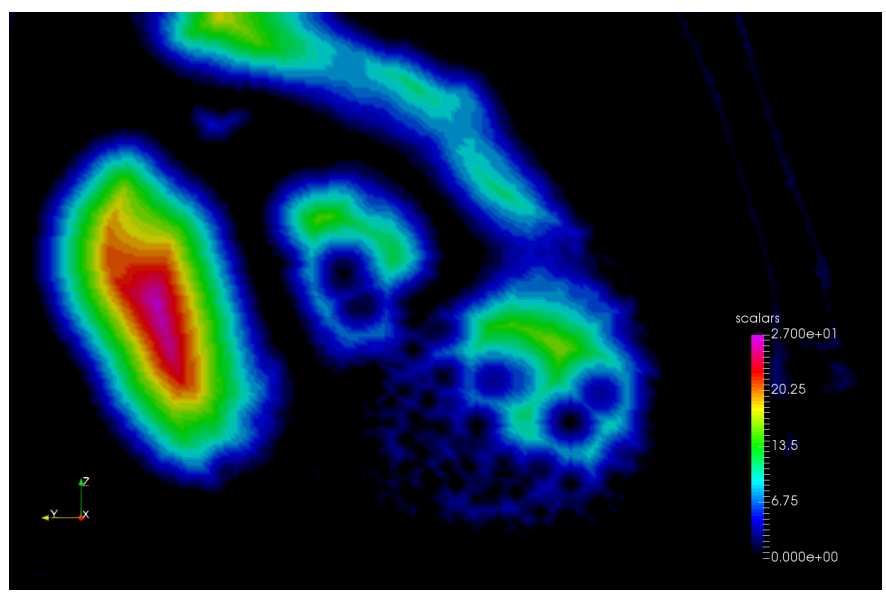

Figure 1. One slice from Euclidian transform image. Color of each voxel shows the distance to the nearest background voxel.

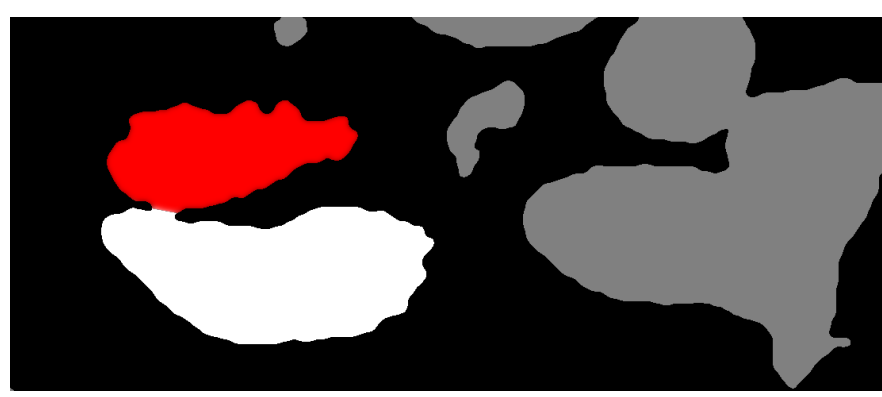

Figure 2. One slice from thresholded image from a dataset. Slice shows LAA (red) and left pulmonary vein (white).

All calculations are performed on thresholded image. First three segmentation steps are guided by the largest radius of a sphere at each voxel. For that reason Euclidian distance transform is calculated on the entire image. For each voxel of the thresholded image we calculate the largest radius of the sphere centered in that voxel. The largest radius is calculated by increasing the radius of the sphere until the sphere first touches a background voxel of the image. For each voxel of thresholded image the radius is saved to the Euclidian transform image. An ilustration of one slice of Euclidian transform image is visible in Fig. 1.

Calculation of Euclidian transfrom image is the most computationally expensive step of the whole method. For our datasets computation of such image lasts around 5 minutes on average PC (Intel i5, 8GB RAM). After the image is generated, all other segmentation steps are performed in 1020 seconds, depending on the dataset. Reason for this is that after the distance transform image is calculated, for all other operations where finding a maximum sphere radius at a certain voxel is necessary, radius values are simply looked up from the distance transform image.

\section{A. Leaks}

Main problem with using any region growing algorithm to segment LAA based on thresholded image is that LAA varies wildly in its shape, size, location and direction. Often LAA is close to other anatomical structures, e.g. pulmonary veins, other arteries. Because of the movement of the heart while acquiring CT images and thin walls of LAA and neighboring anatomical structures, after thresholding it is possible that LAA "touches" some other anatomical structure other than left atrium. Example of this can be seen in Fig. 2. where it is evident that after thresholding LAA and left pulmonary vein are connected. Our proposed method is robust to such leaks, as expained in following sections.

\section{B. Centerline detection}

Starting from first seed point (starting point) centerline detection works iteratively until voxel in current iteration reaches inside of the sphere determined by radius at second seed point (ending point). All voxels in starting seed point's 26neighborhood are added to the list. In each iteration the method finds the voxel with maximum radius in the list, removes it from the list, adds all voxels of it's 26-neighborhood to the list and marks it as a part of the centerline. This ensures that voxels added to the centerline are always in the center of LAA, while the direction in which the centerline grows will be towards the region with larger radius values, which is the atrium. That way centerline detection will be robust to leaks, because leaks are never as big as the width of the LAA.

All possible candidates for the next centerline voxel (all 26-neighbors of any voxel added to centerline) are kept in a list and the centerline voxel in next iteration is always the one with the maximum radius in the list. This ensures that even if the centerline starts to move in the wrong direction, after adding all maximum radius voxels in that part of the LAA it will always move back towards the left atrium, so the centerline will always eventually enter the left atrium, where the centerline detection will stop after entering the sphere determined by the ending seed point.

\section{Initial segmentation based on detected centerline}

Initial segmentation is performed after centerline detection. Methods iterates through every voxel of detected centerline and adds its sphere to segmentation. Figure 3. shows the detected centerline and initial segmentation. It is evident from the figure that the thickness of LAA is not continually increasing from the seed point to the end of centerline, but contains bodges along its length. That is why centerline is wider in those parts, and with it the inital segmentation is also wider. Centerline "picks up" voxels with larger radius in those wider parts and continues in the general direction of left atrium.

\section{Additional iterative decreasing radii segmentation}

After the initial segmentation the method performs an additional segmentation step. For each voxel at the edge of segmentation algorithm determines whether the sphere in that voxel will be added to the segmentation. Each iteration goes through all edge voxels and if at least one sphere was added to the segmentation the algorithm will continue to the next 


\begin{tabular}{|c|c|}
\hline Dataset & DICE Coefficient \\
\hline $\mathbf{1}$ & 0.94667 \\
\hline $\mathbf{2}$ & 0.94239 \\
\hline $\mathbf{3}$ & 0.90811 \\
\hline $\mathbf{4}$ & 0.91817 \\
\hline $\mathbf{5}$ & 0.92975 \\
\hline $\mathbf{6}$ & 0.92250 \\
\hline $\mathbf{7}$ & 0.93307 \\
\hline $\mathbf{8}$ & 0.83837 \\
\hline
\end{tabular}

iteration. If no spheres were added in an iteration, algorithm stops.

For each voxel a sphere to be added to the segmentation is the sphere centered in that voxel where the sphere radius is the shortest distance to any background voxel of thresholded image. Let the currently observed voxel be $\mathbf{V}_{\text {current }}$, let the radius of the sphere in $\mathbf{V}_{\text {current }}$ be $r\left(\mathbf{V}_{\text {current }}\right)$, and let the sphere in $\mathbf{V}_{\text {current }}$ be $S_{\text {current }}$. Algorithm finds the voxel in the unsegmented part of $S_{\text {current }}$ with the maximum radius. Let that voxel be $\mathbf{V}_{\text {rmax }}$. Sphere $S_{\text {current }}$ will be added to the segmentation only if the $r\left(\mathbf{V}_{\text {rmax }}\right) \leq r\left(\mathbf{V}_{\text {current }}\right)$.

Figure 4. shows the spheres added to the segmentation in each iteration. It should be noted that Fig. 4. shows only five iterations of additional segmentation (iteration one being the initial segmentation from previous step), while in reality for this dataset segmentation ran for 14 iterations. That is the reason why the tip of the LAA in Fig. 3. is longer that in Fig. 4.

\section{E. Addition of isolated components}

At this point in segmentation the majority of LAA is already segmented, but in some datasets there can be parts of LAA that have not been added. For example, if the LAA has a narrow and then a wider part and that part was not added to initial segmentation (e.g. it's near the tip of LAA), additional segmentation step will not enter that part because at least one voxel in the wider part will have radius larger than voxels in narrow part of the LAA and that part of LAA will not be added to the segmentation. This problem is solved by two operations. First we apply morphological dilation with spherical structuring element of radius 2 to the segmentation. The purpose of this is to make sure that the segmented voxels of the LAA are as close to the background as possible, so there is no contact between unsegmented parts of the LAA.

After that method performs isolated components labeling with segmented LAA as label 1 and all other isolated components with their own labels. Now all isolated components which are touching the LAA are either parts of the LAA or they are other parts of the heart. Since all other parts of the heart are connected, they are all one big isolated component and volume of that component will be significantly larger than LAA. Afterwards, we add to segmentation any isolated component touching the LAA whose volume is smaller than the currently segmented part of LAA.

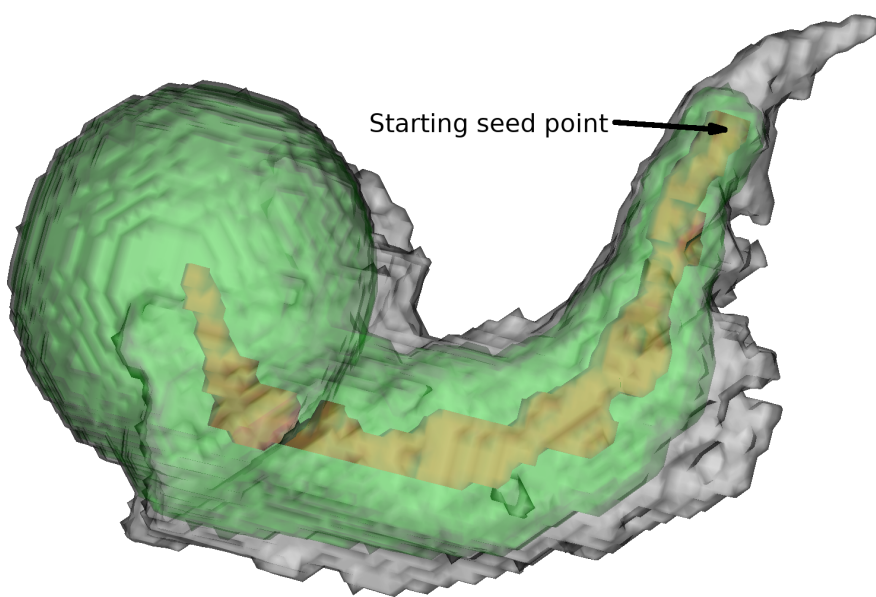

Figure 3. Segmented LAA showing: final segmentation (white), initial segmentation (green) and detected centerlines (orange).

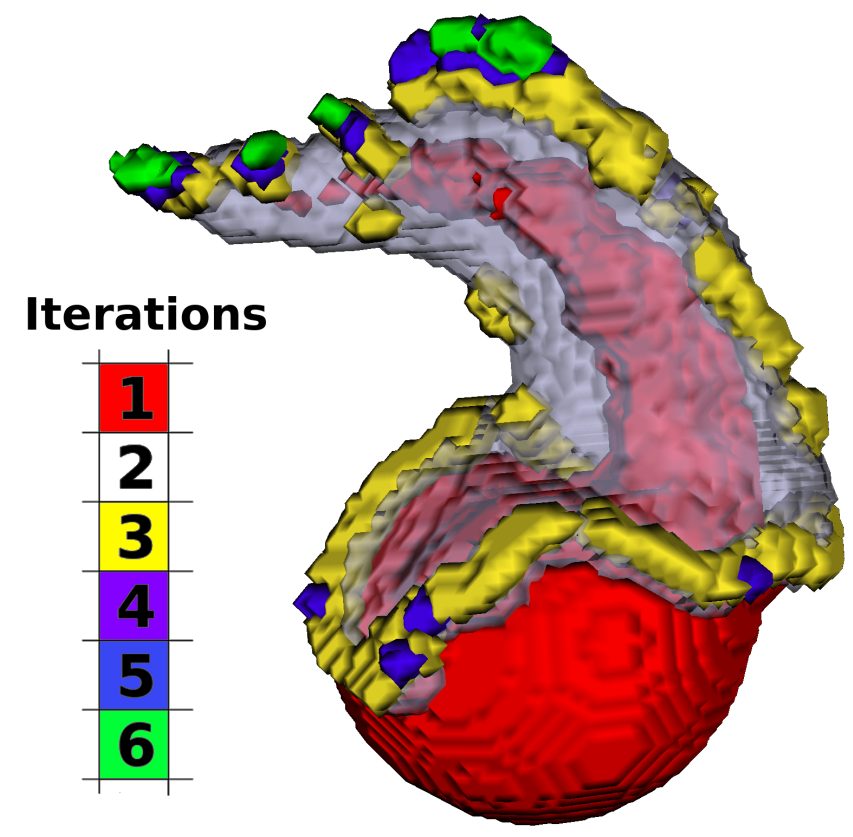

Figure 4. Iterations of the additional decreasing radii segmentation.

\section{RESULTS}

The segmentation results are evaluated on 8 CCTA datasets manually segmented by cardiovascular surgeon using ITKSNAP software [10]. All DICE coefficient are calculated after the points of the cutting plane are selected. Figure 5. shows 6 of 8 resulting segmentations. White color shows segmentation by our method, while red color shows ground truth. Since our method is threshold based, it is evident that our method segments a bit larger area than ground truth, but in all datasets it retains the shape. Blue plane in images shows the location of cutting plane on each dataset. Red, green and blue spheres in images are points which define the cutting plane, which are selected by user after the segmentation is performed. Both models (ground truth and result from our segmentation) are 


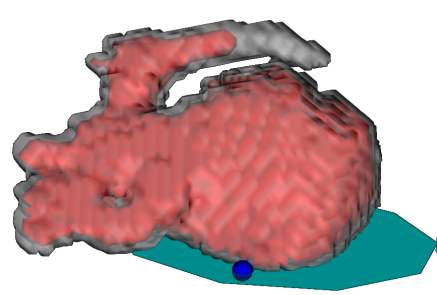

dataset1

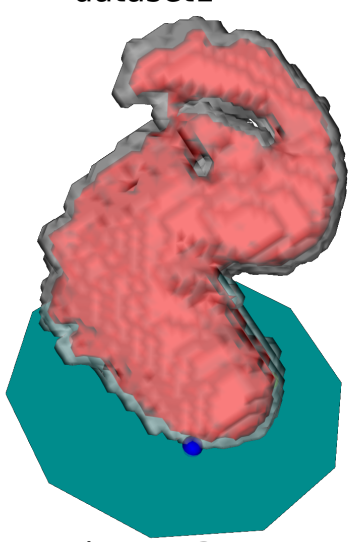

dataset3

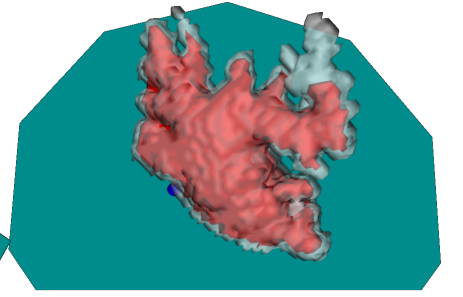

dataset2

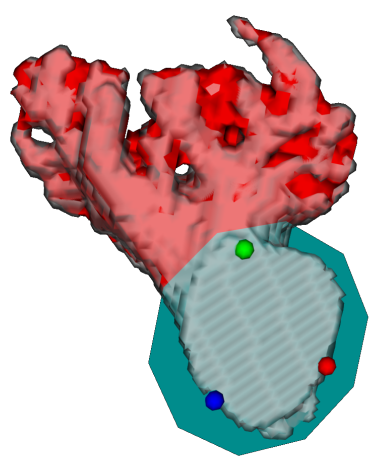

dataset4

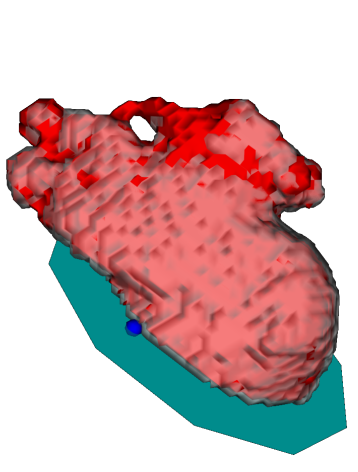

dataset7

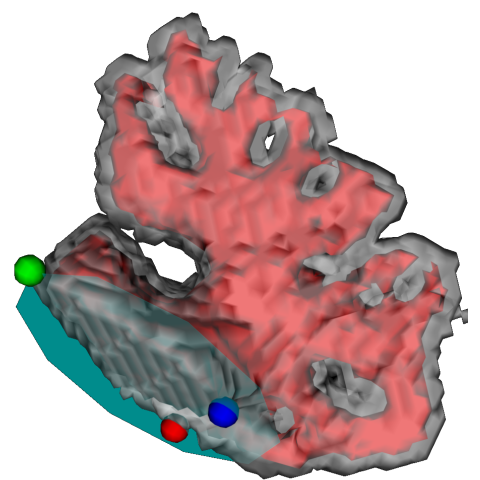

dataset8
Figure 5. Segmentation results after cutting

cut by that plane and overlap (DICE coefficient) is calculated.

Our method achieves a $91.7 \%$ DICE coefficient compared to ground truth. Lowest score of all datasets is $83.4 \%$ on dataset 8 , but shape of LAA is still properly determined. Table I shows dice coefficients achieved on each of the 8 datasets.

\section{CONCLUSION}

In this paper we proposed a novel semi-automatic LAA segmentation method using two seed points (starting and stopping points for segmentation) and manually selected threshold. Method performs LAA centerline detection directed by seed points. Afterwards, multi step spherical region growing based on detected centerline is performed to fully segment the LAA. After segmentation the LAA is visualized and user can select three points defining the ostium of LAA. Proposed method is evaluated on 8 CCTA datasets manually segmented by a cardiovascular surgeon and it achieves a DICE coefficient of $91.7 \%$ on evaluation datasets.

In future we will modify the method to automatically detect the optimal threshold for segmentation and to automatically determine the right criteria for stopping the centerline detection step. These modifications will make the method "singleclick" method, where the user will only have to set a single seed point and our method will preform all other segmentation and visualization steps automatically.

\section{REFERENCES}

[1] L. P. Budge, K. M. Shaffer, J. R. Moorman, D. E. Lake, J. D. Ferguson, and J. M. Mangrum, "Analysis of in vivo left atrial appendage morphology in patients with atrial fibrillation: A direct comparison of transesophageal echocardiography, planar cardiac CT, and segmented three-dimensional cardiac CT," Journal of Interventional Cardiac Electrophysiology, vol. 23, no. 2, pp. 87-93, Nov. 2008, +.

[2] M. E. Goldman, L. A. Pearce, R. G. Hart, M. Zabalgoitia, R. W. Asinger, R. Safford, J. L. Halperin, S. P. i. A. F. Investigators, and others, "Pathophysiologic correlates of thromboembolism in nonvalvular atrial fibrillation: I. Reduced flow velocity in the left atrial appendage (The Stroke Prevention in Atrial Fibrillation [SPAF-III] study)," Journal of the American Society of Echocardiography, vol. 12, no. 12, pp. 1080-1087, 1999.

[3] S. S. Chugh, R. Havmoeller, K. Narayanan, D. Singh, M. Rienstra, E. J. Benjamin, R. F. Gillum, Y.-H. Kim, J. H. McAnulty, Z.-J. Zheng, M. H. Forouzanfar, M. Naghavi, G. A. Mensah, M. Ezzati, and C. J. L. Murray, "Worldwide Epidemiology of Atrial Fibrillation: A Global Burden of Disease 2010 Study," Circulation, p. CIRCULATIONAHA.113.005119, Dec. 2013.

[4] R. G. Hart, O. Benavente, R. McBride, and L. A. Pearce, "Antithrombotic Therapy To Prevent Stroke in Patients with Atrial FibrillationA Meta-Analysis," Annals of internal medicine, vol. 131, no. 7, pp. 492$501,1999$.

[5] S. H. Ostermayer, M. Reisman, P. H. Kramer, R. V. Matthews, W. A. Gray, P. C. Block, H. Omran, A. L. Bartorelli, P. Della Bella, C. Di Mario, C. Pappone, P. N. Casale, J. W. Moses, A. Poppas, D. O. Williams, B. Meier, A. Skanes, P. S. Teirstein, M. D. Lesh, T. Nakai, Y. Bayard, K. Billinger, T. Trepels, U. Krumsdorf, and H. Sievert, "Percutaneous Left Atrial Appendage Transcatheter Occlusion (PLAATO System) to Prevent Stroke in High-Risk Patients With Non-Rheumatic Atrial FibrillationResults From the International Multi-Center Feasibility Trials," Journal of the American College of Cardiology, vol. 46, no. 1, pp. 9-14, Jul. 2005.

[6] V. Y. Reddy, D. Holmes, S. K. Doshi, P. Neuzil, and S. Kar, "Safety of Percutaneous Left Atrial Appendage Closure: Results From the Watchman Left Atrial Appendage System for Embolic Protection in Patients With AF (PROTECT AF) Clinical Trial and the Continued Access Registry," Circulation, vol. 123, no. 4, pp. 417-424, Feb. 2011.

[7] J. Saw, P. Fahmy, R. Spencer, R. Prakash, P. Mclaughlin, S. Nicolaou, and M. Tsang, "Comparing Measurements of CT Angiography, TEE, and Fluoroscopy of the Left Atrial Appendage for Percutaneous Closure," Journal of Cardiovascular Electrophysiology, vol. 27, no. 4, pp. 414-422, Apr. 2016.

[8] L. Wang, J. Feng, C. Jin, J. Lu, and J. Zhou, "Left Atrial Appendage Segmentation Based on Ranking 2-D Segmentation Proposals," in Statistical Atlases and Computational Models of the Heart. Imaging and Modelling Challenges. Springer, Cham, Oct. 2016, pp. 21-29.

[9] H. Zhong, Y. Zheng, G. Funka-Lea, and F. Vega-Higuera, "Segmentation and removal of pulmonary arteries, veins and left atrial appendage for visualizing coronary and bypass arteries," in Computer Vision and Pattern Recognition Workshops (CVPRW), 2012 IEEE Computer Society Conference On. IEEE, 2012, pp. 24-30.

[10] P. A. Yushkevich, J. Piven, H. C. Hazlett, R. G. Smith, S. Ho, J. C. Gee, and G. Gerig, "User-guided 3D active contour segmentation of anatomical structures: Significantly improved efficiency and reliability," NeuroImage, vol. 31, no. 3, pp. 1116-1128, Jul. 2006. 